J. Product. \& Dev., 18(1):85- 100 (2013)

\title{
STUDIES OF SOME FACTORS AFFECTING POST-HARVEST TREATMENTS ON SPEARMINT
}

H.R.A. Mehasen; A.H. M. Kassem and S. M. Mohsen

MAPs Department, Horticulture Research Institute, Agricultural Research Center, Giza, Egypt.

\begin{abstract}
This study was during the years 2009/2010-2010/2011 in order to assess the best way to harvest, the best method for drying, packaging and also for drying and the impact on microbial load and content of volatile oil and the percentage of the active ingredients in mint oil in Spearmint.

The results showed that the best way to harvest is to harvest using sterile gloves so that the herb is traded total in clean plastic boxes. The results also confirmed that the best method for drying was solar drying and the best type of containers during storage was carton boxes packaging. On the other hand results showed that the volatile oil had less increase of active ingredients in the herb, the more storage period and also turns out that there is a steady increase in the rate of microbial load in the grass stock up storage period.

Conclusively, from the previous study showed a decrease in the percentage of essential oil and its components, as well as, increase microbial load with increasing storage period.
\end{abstract}

Key words: Postharvest, Spearmint, Quality. Harvesting, Solar.

\section{INTRODUCTION}

Spearmint Fam. Lamiaceae (Labiatae) is indigenous in Europe and now widespread in cultivation throughout all regions of the world. It is found wild occasionally with its parent species (Ozguven and Kirici, 1999). Spearmint has a high Carvon content, and is often used as a flavoring in tea, ice cream, confectionery, chewing gum, and toothpaste. The oil also contains menthone and menthyl esters. It is the oldest and most popular flavor of mint-flavored confectionery (Oyedeji and Afolayan, 2005).

Production and exportation of Herbs, Medicinal and Aromatic Plants (HMAPs) faces many constraints i.e., high level of pesticides residues, shortage of applying GAP which led to high microbial load and use of old techniques in postharvest and processing (Shalaby et al,1988). 
Postharvest processes are very important in the production of HMAPs since they affect significantly the quantity and quality of these crops. Post harvest starts from the time of harvest or collection. The time at which each crop is collected is usually of considerable importance. Postharvest technology includes drying, grinding, packaging, storage and essential oil extraction.

Drying constitutes the most important processing step in postharvest technology. The main object of drying is to reduce moisture content present at harvest time to a safe limit (8-12\%) (Muller et al, 1996). At this moisture level, the chances of insect and mold infestation are minimized, and thus the commodity can be kept well (Mohamed, 2005 and Fatouh et al, 2006).

Since HMAPs contain volatile aromatic principals, the loss of these volatiles and absorption of foreign odors as a result of inefficient packaging may pose serious problems. HMAPs can be packaged in bags designed to minimize water loss. When HMAPs are packaged by this way, it is particularly important to maintain constancy of fungal or bacterial growth. The bags may be partially permeable to water vapor. The relative humidity in the packaging area, cold rooms, and transport vehicles should be maintained at a high level (> $95 \%)$ where particle (AI-Kershi, 2003).

Storage is an important stage for successful marketing. In the absence of proper storage conditions, HMAPs not only lose their characteristic aroma, color and flavor (Stafford et al, 2004), they also pick up moisture, become moldy and unattractive, then spoilage sets in. (Mimica et al, 2003). In this way the type of storage packages is an important factor which affects of HMAPs marketing (Tomkins and Chcnnell, 2000).

Therefore, the aim of study to assess the best way to harvest, the best method for drying, packaging and also for drying and the impact on microbial load and content of volatile oil and the percentage of the active ingredients in mint oil in Spearmint.

\section{MATERIALS AND METHODS}

This study was during the years 2009/2010- 2010/2011 in order to assess the best way to harvest, the best method for drying, packaging and also for drying and the impact on microbial load and content of volatile oil and the percentage of the active ingredients in mint oil in Spearmint on a 0.25 faddan in an organically certified Farm managed by Omar Ibn Alkhattab Association to study harvesting practices, handling, drying methods, packaging and storage period on spearmint quality. The treatments were as follows:-

\section{1: Harvesting and handling treatments:}

- Three harvesting treatments were used as follows:- 
1- The traditional harvesting in which the herb was collected by bare hands (T1).

2-The herb using sterile hand and tools dipped in Dettol (5\% for 10 seconds) (T2).

3- The laborers wore gloves and protection gears for head and feet (T3).

- Three handling treatments were used as follows:-

(1)- Traditional method: The harvested herb was put directly on the ground (C1- control).

(2) - The harvested herb was put directly on plastic sheet (C2).

(3) - The harvested herb was put directly in clear plastic containers (C3).

\section{2- Drying methods:-}

- Three drying methods were used as follows:-:

1- Natural drying involves placing the herb on craft paper in the sun for 24 hours then transferring it into the shade (D1).

2- The second method involves drying spearmint in direct sun (D2).

3- The third method is Solar drying involves using a tunnel solar drying facility (D3).

\section{3-Packaging process:-}

Three packaging types (plastic cases, Jute cases and carton boxes) were used for each drying method. The samples of dried spearmint herb were packed and stored for two years in standard storage room in the same farm where the temperature was $(25 \pm 1)$ and the relative humidity ranged was from 25 to $40 \%$.

Each treatment included three replicates and each replicate was 5 kilogram of spearmint dry herb. The stored samples of the dry herb in the different packages were studied for the tested characters in zero time of storage in Sep and every four months (Jan, May and Sep) for two years.

\section{Data recorded}

- Total Microbes Count (TMC) per gram sample of all treatments was determined using nutrient agar medium according to the procedure described by (Merck, 1977).

- Volatile oil percentage and volatile oil content of fresh and dry herb for each sample were determined using the method described in British pharmacopoeia (1963).

- GLC analysis as outlined by Harris (2003). For the chemical composition of spearmint essential oil of each treatment, was carried out at the central herb of chemical analysis-National Research Center. 


\section{- Statistical analysis}

The experiment was designed in Complete Randomized blocks design and was statistically analyzed by Costat analysis program using LSD at 5\% level according to Snedecor and Cochran (1967).

\section{RESULTS AND DISCUSSION}

\section{Effect of harvesting and handling methods on TMC:}

The results showed in Table (1) significant decrease in microbial load as a result of harvesting and handling transactions for the herb after harvest and the interaction between the treatments.

On the same approach; the harvesting with sterile gloves was one of the best transactions, followed by hand sanitizer and tools where gave lowest rate of microbial load $(1.10 \& 2.64$ million/ $\mathrm{g}$ in the first season. and $1.08 \& 2.33$ million/ $\mathrm{g}$ in the second season, respectively). However, the traditional method of harvesting (by hands) gave the highest average of TMC $(8.37 \& 7.66$ million/ g in the first and second season), which may due to infestation by microbes through labor hands to the harvested herb.

Also results showed that the lowest rate of the microbial load was when trading in clean plastic containers (1.03 and 1.5 million/ $\mathrm{g}$, respectively). On the other hand, the Plants were harvested and placed on the ground with a very high rate of the microbial load $(8.37 \& 7.66$ million/ g). This may be due to the transmission of microbial load from contaminated land to the harvested herb. The most important results obtained is that the lowest rate of the microbial load in mint herb harvested sterile gloves, which were traded in sterile plastic containers ( $0.66 \& 0.74$ million/ g) (T3 X C3). The results were also, similar in case of T2X C2 treatment, the TMC showed insignificant differences comparing with T3 C3 treatment. The results confirmed that the harvesting and trading of herb by traditional methods ( $\mathrm{T} 1$ and $\mathrm{C} 1$ ) gave the highest average of TMC (7.1 million/g).

It can be certain that the use of sterile gloves with sterile clean trading of the harvested herb reduces microbial load to the lowest level. These results were in agreement with Zheljazkov et al (1999).

2. Effect of drying methods, storage packaging and storage period on TMC (million/g.), volatile oil content and oil components of spearmint:

A- Effect of drying methods, storage packaging and storage period on TMC (million/g.)

Data presented in Table 2, showed significant differences in microbial load average in dried spearmint because of the way the drying and storage period 
Using carton boxes or plastic cases proved the best materials for storage dry herb for long periods with less TMC. This can be explained on the basis of studies of suggestions of AI-Kershi (2003) and Mehasen et al. (2009).

Accordingly, data in Table (2), in general found that the use of carton boxes was the best in keeping dry herb for the duration of storage compared to other packages. As the dry grass in the solar system powder was the best in less than a percentage of TMC. Also, it was found that, lowest average of TMC in spearmint dry herb was recorded in case of solar drying method and storing the dried herb in carton boxes or plastic cases during the storage period. Values were found to be statistically the same for plastic cases and carton boxes. These results were in agreement with Manuel et al. (2008) and Mehasen et al. (2009).

\section{2. b.-Volatile oil percentage and the active ingredients: \\ b-1- Volatile oil percentage:}

Data presented in Table 3 showed significant differences in volatile oil percentage through the zero time storage, after four months, after herb storage for eight months and one year storage which due to the effect of storage treatments.

Data also, indicated that, volatile oil of spearmint herb was found to be affected by drying methods. The highest volatile oil content was recorded in case of solar drying method (1.62 and $1.54 \%$ for each season, respectively); while the lowest one was found in direct sun drying (1.53 and $1.45 \%$ for each season, respectively). The differences between the values of volatile oil content of the three drying methods were significant.

It could be concluded that, the best drying method was solar drying system in which the evaporation of volatile oil of the spearmint herb was less than the other drying methods. As for the storage period, data also indicated by storage period. It was found that, volatile oil content gradually decreased as the storage period was increased.

So, spearmint volatile oil percentage was 1.57 and $1.49 \%$ average for each season respectively in zero time (Sep. 2009) then this value was decreased to 1.35 and $1.20 \%$ after four months, 1.28 and $1.24 \%$ after eight months while, the lowest decrement (1.20 and 1.12\%) was recorded after one year storage for each season, respectively, regardless the storage packages.

Concerning the packaging types and its effect on volatile oil percentage of spearmint dried herb, it was pointed out that, the packaging type was found to be either preserved the volatile oil percentage of spearmint dried herb, or led to a sharp decrement, this trend was clearly showed throughout the storage period. Accordingly, the highest volatile oil percentage was detected in case of carton boxes, while the lowest one found in plastic cases. Data also, emphasized that, an interaction was found between the three 
factors that used in this study. It was found that, after one year storage period the highest volatile oil percentage was determined in spearmint herb with using solar drying method and packaging in carton boxes the value in this respect were 1.35 and $1.20 \%$ in the two seasons. On the contrary, lowest value of spearmint oil percentage was obtained after one year storage with using plastic cases and Jute cases regardless the drying method.

On the light of these findings, it could be concluded that the best quality of spearmint herb ( in view of oil percentage) was obtained by using solar drying method for dried herb in carton boxes for a period prolonged to one year. In this case the volatile oil percentage was $1.20 \%$ comparing to $1.57 \%$ at the zero time (Sep 2010) in the first season. Also, the volatile oil percentage was $1.12 \%$ comparing to $1.49 \%$ at the zero time (Sep 2011) in the second season. The reduction in volatile oil percentage was estimated by $13.16 \%$ after one year storage.

In addition, the results showed that the best drying system, which gave the highest percentage in spearmint oil, was solar drying system. In addition, the storage package, which gave the highest percentage volatile oil, was carton. Similarly, the highest percentage of spearmint volatile oil after one year storage (1.36 and $1.32 \%)$ occurred with using solar drying system with carton boxes (D1or D3+ carton).

In general, the data reported that the volatile oil percentage of spearmint from the dried herb with the three dry methods was decreased through the storage period from zero time to one year storage. Also, the best storage packaging was the carton which gave the lowest decreasing level in the oil percentage. These results may due to those post harvest treatments may be affect the chemical composition and biological activity of medicinal plant material. These include the common practices of drying and re-dissolving plant extracts; various filtering methods; the application of heat and; the use of liquid nitrogen to grind plant material. Information, such as storage period and conditions, therefore, should be noted and included in published results. Since accelerated ageing (Stafford et al, 2004, Asekun et al, 2007 and Mehasen et al. (2009). allows plant material to be rapidly aged, studying the effects of storage on plant material is less time consuming. This is especially relevant to medicinal plant materials traded in traditional African markets, most of which are exposed to high temperatures and/ or humidity levels, such as those experienced in coastal regions like Durban which has one of South Africa's largest markets.

\section{b-2- The active ingredients' percentage (Carvon, Limonene and 1,8-Cineolea):}

The data in Table 4 indicated that the solar drying method in solar drying system gave the highest percentage of Carvon in Spearmint oil 
followed by the shade drying and direct sun drying (54.2, 50.33 and $49.1 \%$, in the first season respectively while the results in the second season were 53.2, 49.33 and $48.1 \%$, respectively). The differences between the values of Carvon percentage of the three drying methods were significant. So, it could be reported that, the best drying method was solar drying system in which the evaporation of volatile oil of the spearmint herb was less than the other drying methods. As for the storage period, data also indicated by storage period. It was found that, Carvon percentage gradually decreased as the storage period was increased. So, Carvon percentage for each season were 51.1 and $50.1 \%$ average in Zero time (Sep.2009 and Sep 2010) then this values were decreased to 45.3 and $44.3 \%$ after four months, 41.0 and $40.1 \%$ after eight months and the lowest decrement (39.3 and $38.3 \%$ ) was recorded after one year storage for each season respectively, regardless the storage packages.

For Limonene percentage in spearmint essential oil the data in Table (5) indicated that the solar drying method gave the highest percentage of Limonene in spearmint oil followed by the shade drying and direct sun drying $(37.3,33.1$ and 32.1 in the first season respectively while the results in the second season were $38.3,32.1$ and $33.1 \%$, respectively). The differences between the values of Limonene percentage of the three drying methods were significant.

So, it could be reported that, the best drying method was solar drying system in which the evaporation of volatile oil of the spearmint herb was less than the other drying methods. As for the storage period, data also indicated by storage period. It was found that, Limonene percentage gradually decreased as the storage period was increased. So, Limonene percentages were 34.17 and $35.1 \%$ average in zero time (sep.2009 and sep.2010 respectively) then this values were decreased to 29.1 and $30.1 \%$ after four months, 26.3 and $27.3 \%$ after eight months and the lowest decrement (23.8 and $24.8 \%$ ) was recorded after one year storage for each season, respectively, regardless the storage packages.

For the values of 1,8-Cineolea, the data in Table (6) indicated that the solar drying method gave the highest percentage of 1,8-Cineolea in spearmint oil followed by the shade drying and direct sun drying ((9.2, 6.0 and $5.7 \%$ in the first season respectively while the results in the second season were 9.7 , 6.5 and $6.2 \%$, respectively).

Data also, cleared that, the differences between the values of 1, 8Cineolea content of the three drying methods were significant. So, it could be reported that, the best drying method was solar drying system in which the evaporation of volatile oil of the spearmint herb was less than the other drying methods. As for the storage period, data also indicated by storage period. It was found that, 1, 8-Cineolea content gradually decreased as the storage 
period was increased. So, 1,8-Cineolea percentages were 7.0 and $7.4 \%$ average in zero time (sep.2009 and sep.2010 respectively) then this values were decreased to 6.0 and $6.5 \%$ after four months, 4.8 and $5.3 \%$ after eight months and the lowest decrement (4.0 and $4.5 \%$ ) was recorded after one year storage for each season respectively, regardless the storage packages

In general, the results also showed that the packaging type was found to be either preserved the Carvon, Limonene and1,8-Cineolea percentage of spearmint dried herb, or led to a decrement, this trend was clearly showed for each out the storage period. Accordingly, the highest Carvon, Limonene and1,8-Cineolea contents were detected in case of carton boxes, while the lowest one found in plastic and Jute cases. Data also, reported that, an interaction was found between the three factors that used in this investigation. It was found that, after one year storage period the highest Carvon, Limonene and1,8-Cineolea content was determined in spearmint herb with using solar drying method and packaging in carton boxes.

In general, the ratio of Carvon, Limonene and1, 8-Cineolea decreased through storage period and the lowest decrement was with shad drying treatment in the carton package; however, the highest decrement was with solar and direct sun dried mint in the plastic and Jute cases.

\section{RECOMMENDATIONS}

- In order to get the best product of spearmint is identical to the export specification, the study confirmed that the harvest sterile instruments or wear sterile gloves and then traded grass in sterile plastic containers reduces significantly the microbial load average.

- The best drying system in the study was the solar drying system.

- The best storage containers in the previous study were the cartoon boxes.

- Solar drying system and packing in carton boxes gave the best content of volatile oil and the lowest rate of microbial load and the best ratio of the active components of the essential oil.

- The previous study showed a decrease in the percentage of essential oil and its components, as well as, increase microbial load with increasing storage period.

\section{REFERENCES}

Al-Kershi, A. A. G. (2003). Postharvest packaging and temperature controlled storage of spearmint and sweet Basil herbs destined for medicinal and aromatic uses. Ph.D. Thesis, Faculty of Agriculture, Alexandria University, Egypt. 
Asekun, O.T., Grierson D.S. and Afolayan A.J. (2007). Effects of drying methods on the quality and quantity of the essential oil of Mentha longifolia L. subsp. Capensis, Food Chemistry, 101:995-998.

British Pharmacopoeia, (1963). The Pharmaceutical Press 17 Bloomsburg, Square. W.C.I. London.

Fatouh, M; Metwally, M. N; Helali, A. B; Shedid, M. H.(2006). Herbs drying using a heat pump dryer. Energy Conversion and Management. 47(15/16): 2629-2643.

Harris, Dadiel C. (2003). Quantitative Chemical Analysis 6th Edition. New York: W.H. Freeman.

Manuel Aira, Fernando Monroy and Jorge, A.M. (2008). Dominguez Changes in bacterial numbers and microbial activity of pig slurry during gut transit of epigamic and anemic earthworms Journal of Hazardous Materials, 162: 1404-1407.

Merck, E. (1977). "Microbiology" Dehydrated Culture media Bases Sundry Preparation for Microbiology. Darmstadt, Federal Republic of Germany.

Mehasen.H.R.A. ; A.M.A Hamouda and S.G.I.Soliman (2009). Effect of some postharvest treatments on peppermint quality. Egyptian Journal of Horticulture, 71(312-320).

Mimica, D. N., Bozin, B., Sokovic, M., Mihailovic, B and Matavulj, M. (2003). Antimicrobial and antioxidant activities of three Mentha species essential oils. Plant Medica, 69(5): 413-419.

Mohamed S.M.A. (2005). Effect of storage on some medicinal plants in Egypt and Morocco M.Sc. Thesis, Faculty of Agriculture, Cairo University, Egypt,: 88-104.

Muller, J; Conrad, T.; Thome, B and Muhlbauer, W. (1996). Drying of medicinal plants in a plastics solar drier .Institute fur Agrartechnik in den Tropen und Subtrahend, Universidad

Oyedeji, O. A. and Afolayan, A. J. (2005). Chemical composition and antibacterial activity of essential oil of the African Mentha longifolia. Journal of Pharmacology, 99: 144-156.

Ozguven, M and Kirici, S. (1999). Research on yield, essential oil, contents and components of mint (Mentha) species in different ecologies. Turkish Journal of Agriculture and Forestry, 23 (5): 465-472.

Shalaby, A.S; El-Gamasy, A. M; El-Gengaihi, S. E and Khattab, M. D. (1988) Postharvest studies on herb and oil of Mentha arvensis L. Egyptian Journal of Horticulture, 15 (2): 213-224.

Snedercor, G.W. and Cochran, W.G. (1967). Statistical Methods. Iowa State University, Press Amer, Iowa, USA. 
Stafford, G.I., J“ager, A. K. and Van Staden, J.( 2004). Effect of storage on the chemical composition and biological activity of several popular South African medicinal plants. Journal of Ethno Pharmacology (in review).

Tomkins, R. and Chennell, A. (2000). Storing and Handling Culinary Herbs. Institute for Horticultural Development, Victoria. Kura Industries Research of Development Corporation 69.

Zheljazkov, V. D.; Jeliazkova, E. A.; Craker, L. E.; Yankov, B.; Georgieva, T.; Kolev, T.; Kovatcheva, N.; Stanev, S.; Margina, A.; Caffini, N. (ed.); Bernath, J. (ed.); Craker, L. (ed.); Jatisatienr, A. and Giberti, G. (1999). Heavy metal uptake by mint Proceedings of Second World Congress on Medicinal and Aromatic Plants, WOCMAP-2. Biological Resources, Sustainable Use, Conservation and Ethno Botany, Mendoza, Argentina, 10-15 November, 1997. Acta-Horticulture, 500, 111-117; 16 ref.

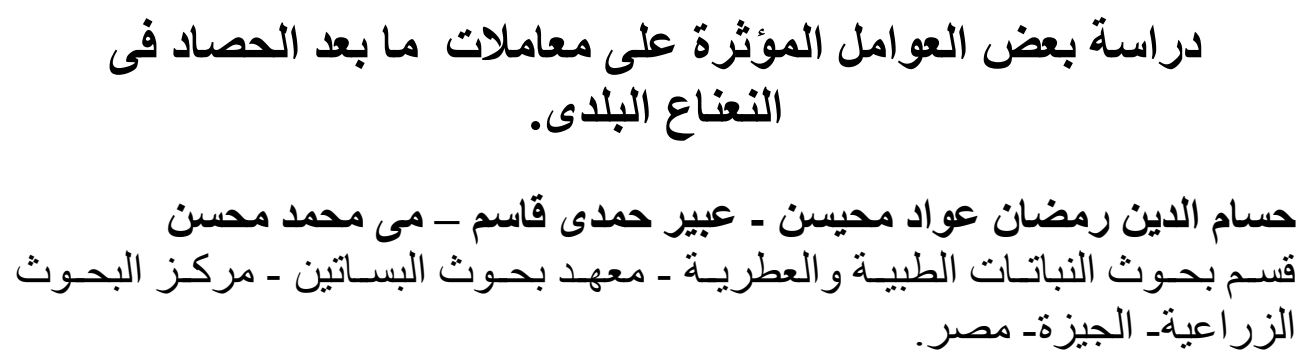

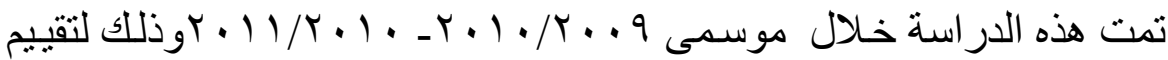

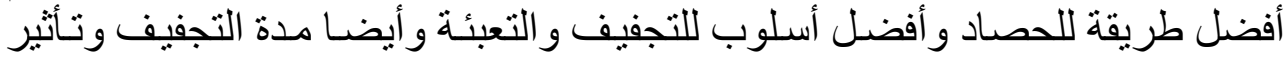

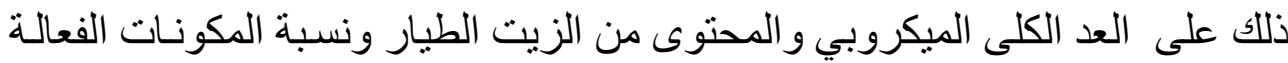
في الزيت لنبات النعناع البلدى.

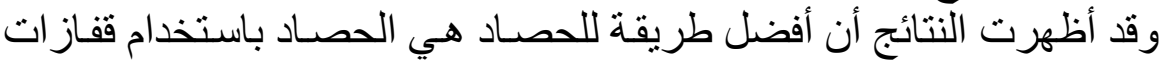

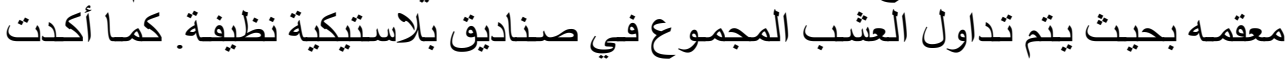

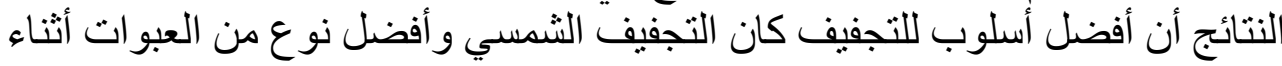
التخزين كانت عبو ات الكرنون.

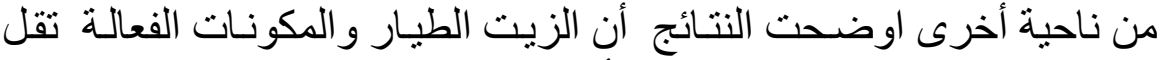

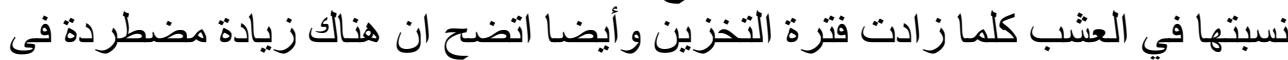
معدل الحمل الميكروبي فى العشب المخزن بزيادة فترة التخزين. 